\section{Hypertensive toxicity of thyrosine kinase inhibitors; Friend or Foe?}

\author{
Ergün Barış Kaya and Yusuf Ziya Şener* \\ Cardiology Department, Faculty of Medicine, Hacettepe University, Turkey
}

\section{Abstract}

Tyrosine kinase inhibitors (TKIs) are widely used in Oncology practice. Hypertension may develop during cancer treatment and TKIs are well known drugs that are associated with drug related hypertensive toxicity. TKI related hypertensive toxicity is not always the indicator of worse clinical outcomes and it may be the sign of treatment efficacy.

The development of new targeted therapies such as tyrosine kinase inhibitors (TKIs) has led to dramatic survival benefit in cancer patients. TKIs affects several pathways including cell proliferation and angiogenesis. Angiogenesis plays crucial role in tumor growth and metastasis, therefore inhibition of angiogenesis is one of the main goals in cancer treatment [1]. Vascular endothelial growth factor (VEGF) is the main mediator of angiogenesis and tyrosine kinase inhibitors (TKIs) which are used in several malignancies including; renal cell carcinoma, hepatocellular carcinoma, medullar thyroid carcinoma, colorectal carcinoma and gastrointestinal stromal tumor have VEGF signaling pathway inhibitory effects [2]. There are three subtypes of VEGF receptors and VEGF exerts its thyrosine kinase pathway related effects via VEGF receptor 2 (VEGFR2). VEGF causes nitric oxide (NO) production, endothelial cell proliferation and migration, increased vascular permeability and survival under stress conditions. VEGF inhibition leads to decreased levels of vasodilatory mediators including $\mathrm{NO}$ and prostacyclin and is also associated with decreased survival of endothelial cells resulting in increased peripheral vascular resistance [3].

Cancer treatment related hypertensive cardio toxicity is graded into 5 classes according to the Common Terminology Criteria for Adverse Events (CTCAE) report. Approach to the patients with different grades of hypertensive cardio toxicity is presented in table 1 . Several anti-cancer drugs other than VEGF inhibitors also may cause hypertensive cardio toxicity [4].

TKI related hypertension usually develops in the first week of the treatment and it is dose dependent in general. Patients who are candidates for TKI treatment should be evaluated before the treatment and blood pressure should be controlled

\section{More Information}

*Address for Correspondence:

Yusuf Ziya Şener, MD, Faculty of Medicine, Cardiology Department, Hacettepe University, Turkey, Email: yzsener@yahoo.com.tr

Submitted: December 23, 2020

Approved: January 11, 2021

Published: January 12, 2021

How to cite this article: Kaya EB, Şener YZ. Hypertensive toxicity of thyrosine kinase inhibitors; Friend or Foe? Ann Clin Hypertens. 2021; 5: 001-002.

DOI: 10.29328/journal.ach.1001025

ORCID: orcid.org/0000-0001-5151-5133

Copyright: @ 2021 Kaya EB, et al.

This is an open access article distributed under the Creative Commons Attribution License, which permits unrestricted use, distribution, and reproduction in any medium, provided the original work is properly cited.

Check for updates

OPEN ACCESS

Table 1: CTCAE Grades of Hypertensive Toxicity and Management.

\begin{tabular}{|c|c|c|}
\hline CTCAE Grade & Definition & Management \\
\hline Grade 1 & $\begin{array}{l}\text {-SBP: } 120-139 \mathrm{mmHg} \\
\text {-DBP: } 80-89 \mathrm{mmHg}\end{array}$ & Lifestyle modification \\
\hline Grade 2 & $\begin{array}{l}\text {-SBP: } 140-159 \mathrm{mmHg} \\
\text {-DBP: } 90-99 \mathrm{mmHg} \\
\text {-Increase of } 20 \mathrm{mmHg} \text { in } \\
\text { DBP with symptoms }\end{array}$ & Drug monotherapy \\
\hline Grade 3 & $\begin{array}{l}-\mathrm{SBP}>160 \mathrm{mmHg} \\
-\mathrm{DBP}>100 \mathrm{mmHg}\end{array}$ & Drug combination \\
\hline Grade 4 & $\begin{array}{c}\text { Malignant hypertension } \\
\text { (Retinopathy with BP }>200 / 120 \mathrm{mmHg} \text { ) } \\
\text { Hypertensive crisis }\end{array}$ & $\begin{array}{l}\text { Urgent parenteral } \\
\text { treatment }\end{array}$ \\
\hline Grade 5 & Death & -- \\
\hline
\end{tabular}

1 week before the TKI administration. Blood pressure should be monitorised during the first cycle of the treatment and it should be checked in every 2-3 weeks until the end of treatment. Target values for blood pressure are $<140 \mathrm{mmHg}$ for systolic pressure and $<90 \mathrm{mmHg}$ for diastolic pressure. Even it is in the target range; increase in diastolic blood pressure more than $20 \mathrm{mmHg}$ should direct the clinicians to start antihypertensive treatment [5].

Proteinuria may develop as a consequence of uncontrolled chronic hypertension and some glomerulonephritis may present with proteinuria and hypertension. In addition, some of the glomerular diseases may occur as paraneoplastic syndrome. It is expressed that VEGF inhibition causes reduction in nephrin production which ends in interruption of the glomerular fenestrated endothelium [6]. Therefore it 
should be kept in mind that thyrosine kinase inhibitors may cause both hypertension and proteinuria.

Although the development of hypertension is result of VEGF inhibitor toxicity; it may also be a sign of treatment efficacy of the anticancer drug. It is shown in SELECT trial that; development of up to Grade 3 hypertensive toxicity during Lenvatinib treatment was associated with better outcomes in patients with metastatic differentiated thyroid carcinoma [7]. Lenvtatinib which is used in advanced stage differentiated thyroid carcinoma and hepatocellular carcinoma is a multikinase inhibitor and it inhibits not only VEGF receptors but also RET and KIT receptors. Therefore; the incidence of hypertensive toxicity is more frequent in patients treated with Lenvatinib than other TKIs [8].

It is reported in a meta-analysis that occurrence after treatment with Sorafenib was related to longer progression free survival and overall survival in different cancer types [9]. Similar prognostically beneficial effects have been observed in Axitinib [10].

Treatment of hypertension in cancer patient is an important goal in order to be able to administer higher effective doses of TKIs and provide patients from hypertension related complications. Choice of antihypertensive drug should be based upon coexisting comorbidities. It should be kept in mind that diltiazem may reduce the effects of anticancer drugs due to drug interactions via CYP450 enzymes. TKIs may cause prolongation of corrected QT; therefore diuretics should not be preferred as frontier lines in treatment due to their possible adverse effects on electroloyte levels. ACE inhibitors and dihydropyridine calcium channel blockers may be the safe option in cases with TKI related hypertension [3].

\section{Conclusion}

Although hypertensive toxicity is an undesirable result of TKI use; it may be the sign of the treatment efficacy and better disease outcomes in cancer patients. If TKI related hypertensive toxicity develop in a patient; TKIs should be discontinued temporarily, antihypertensive treatment should be started and TKI should be read ministered after blood pressure control.

\section{References}

1. Dobbin SJH, Petrie MC, Myles RC, Touyz RM, Lang NN. Cardiotoxic effects of angiogenesis inhibitors. Clin Sci (Lond). 2021; 135: 71-100. PubMed: https://pubmed.ncbi.nlm.nih.gov/33404052/

2. Pottier $C$, Fresnais $M$, Gilon $M$, Jérusalem $G$, Longuespée $R$, et al. Tyrosine kinase inhibitors in cancer: breakthrough and challenges of targeted therapy. Cancers (Basel). 2020; 12: 731. PubMed: https://pubmed.ncbi.nlm.nih.gov/32244867/

3. Ptinopoulou AG, Sprangers B. Tyrosine kinase inhibitor-induced hypertension-marker of anti-tumour treatment efficacy or cardiovascular risk factor? Clin Kidney J. sfaa174.

4. Chung R, Tyebally S, Chen D, Kapil V, Walker JM, et al. Hypertensive Cardiotoxicity in Cancer Treatment-Systematic Analysis of Adjunct, Conventional Chemotherapy, and Novel Therapies-Epidemiology, Incidence, and Pathophysiology. J Clin Med. 2020; 9: 3346.

PubMed: https://pubmed.ncbi.nlm.nih.gov/33081013/

5. Maitland ML, Bakris GL, Black HR, Chen HX, Durand JB, et al. Initial assessment, surveillance, and management of blood pressure in patients receiving vascular endothelial growth factor signaling pathway inhibitors. J Natl Cancer Inst. 2010; 102: 596-604.

PubMed: https://pubmed.ncbi.nlm.nih.gov/20351338/

6. Kandula $P$, Agarwal R. Proteinuria and hypertension with tyrosine kinase inhibitors. Kidney Int. 2011; 80: 1271-1277.

PubMed: https://pubmed.ncbi.nlm.nih.gov/21900879/

7. Wirth LJ, Tahara M, Robinson B, Francis S, Brose MS, et al. Treatmentemergent hypertension and efficacy in the phase 3 study of (E7080) lenvatinib in differentiated cancer of the thyroid (SELECT). Cancer. 2018; 124: 2365-2372.

PubMed: https://pubmed.ncbi.nlm.nih.gov/29656442/

8. Pandey AK, Singhi EK, Arroyo JP, Ikizler TA, Gould ER, et al Mechanisms of VEGF inhibitor-associated hypertension and vascular disease. Hypertension 2018; 71: e1-e8.

PubMed: https://pubmed.ncbi.nlm.nih.gov/29279311/

9. Yang X, Pan X, Cheng X, Kuang Y, Cheng Y. Risk of Hypertension with Sorafenib Use in Patients with Cancer: A Meta-Analysis From 20,494 Patients. Am J Ther. 2017; 24: e81-e101.

PubMed: https://pubmed.ncbi.nlm.nih.gov/26322676/

10. Rini BI, Schiller JH, Fruehauf JP, Cohen EE, Tarazi JC, et al. Diastolic blood pressure as a biomarker of axitinib efficacy in solid tumors. Clin Cancer Res. 2011; 17: 3841-3849.

PubMed: https://pubmed.ncbi.nlm.nih.gov/21531811/ 